\title{
AS POLÍTICAS DE AVALIAÇÃO EM LARGA ESCALA E TRABALHO DOCENTE: DOS DISCURSOS EFICIENTISTAS AOS CAMINHOS CONTRARREGULATÓRIOS
}

\author{
EL TRABAJO DE ENSEÑANZA Y EVALUACIÓN A GRAN ESCALA \\ POLÍTICAS: LOS DISCURSOS EFICIENTISTAS A \\ CONTRARREGULATÓRIOS
}

\section{THE LARGE-SCALE ASSESSMENT POLICIES AND TEACHING WORK: THE SPEECHES EFICIENTISTAS TO CONTRARREGULATÓRIOS}

Ivan AMARO ${ }^{1}$

\begin{abstract}
RESUMO: A avaliação de sistemas educativos assumiu grande relevância no cenário da educação internacional e nacional. Desde meados da década de 1990, no Brasil, ela intensifica-se e avança como peça central na engrenagem em busca da qualidade. Efeitos tem sido gerados no cotidiano das escolas e no trabalho docente. Este artigo discute, prioritariamente, as características performativas, reguladoras e responsabilizadoras que estas avaliações assumem diretamente no trabalho docente. Apresentamos achados de pesquisa realizada em escolas de duas redes municipais localizadas na Baixada Fluminense, região metropolitana do Rio de Janeiro. Tem como objetivo investigar os sentidos e os efeitos que os resultados das avaliações externas, na educação básica têm provocado no desenvolvimento do trabalho docente, focalizando na perspectiva de gestores escolares e professores. A questão disparadora de nossa investigação gerou em torno deste objetivo: como os resultados dos testes estandardizados e do IDEB (Índice de Desenvolvimento da Educação Básica) têm interferido no trabalho docente desenvolvido em suas salas de aula? Dentre os achados, identificamos um amplo processo de intensificação do trabalho docente, acompanhado de responsabilização e desqualificação das professoras. Além disso, há um conjunto de elementos performativos e reguladores que aparecem no cotidiano pedagógico e que caracterizam um viés neotecnicista no trabalho docente.
\end{abstract}

PALAVRAS-CHAVE: Políticas de avaliação. Trabalho docente. Caminhos contraregulatórios.

RESUMEN: La evaluación de los sistemas educativos ha tomado gran relevancia en la educación nacional e internacional. Desde mediados de 1990, en Brasil, se intensifica y avanza como pieza central en el engranaje en la búsqueda de calidad. Efectos se ha generado en la vida cotidiana de las escuelas y en el trabajo. Este artículo discute principalmente rendimiento características, normas reglamentarias y responsables que estas evaluaciones se toman directamente en el trabajo. Presentamos los resultados de investigaciones realizadas en escuelas de dos redes municipales ubicadas en la Baixada Fluminense, la región metropolitana de Río de Janeiro. Tiene como objetivo investigar los sentidos y los efectos que los resultados de las evaluaciones externas, en la educación básica han provocado el desarrollo de la labor docente, centrándose en la perspectiva de directivos de escuela y maestros. ¿El tema desencadenante de nuestra

${ }^{1}$ Professor do Programa de Pós-graduação em Educação, Cultura e Comunicação em periferias urbanas PPGECC, UERJ. Email: ivanamaro.uerj@gmail.com 
investigación ha generado alrededor de esta meta: como prueba estandarizada los resultados y el IDEB (índice de desarrollo de la educación básica) han interferido en el trabajo de enseñanza desarrollado en sus aulas? Entre los resultados, se identificaron un amplio proceso de intensificación del trabajo, acompañado de rendición de cuentas y descalificación de los maestros. Además, es un conjunto de elementos performáticos y reguladores que aparecen en el diario y con un sesgo de neotecnicista en el trabajo.

PALABRAS CLAVE: Políticas de evaluación. Labor del docente. Contrarregulatórios caminos.

ABSTRACT: The evaluation of education systems has taken on great relevance in the international and national education. Since the mid-1990, in Brazil, it intensifies and advances as centerpiece on gear in pursuit of quality. Effects has been generated in the daily life of schools and at work. This article discusses primarily performing characteristics, regulatory and responsible norms that these evaluations take directly at work. We present findings of research conducted in schools of two municipal networks located in the Baixada Fluminense, the metropolitan region of Rio de Janeiro. Aims to investigate the senses and the effects that the results of external evaluations, in basic education have provoked the development of teaching work, focusing on the perspective of school managers and teachers. The triggering issue of our investigation has generated around this goal: as standardized test results and IDEB (basic education development index) have interfered at work teaching developed in their classrooms? Among the findings, we identified a broad process of intensification of work, accompanied by accountability and disqualification of the teachers. In addition, there is a set of performative elements and regulators that appear in the daily and featuring a neotecnicista bias at work.

KEYWORDS: Assessment policies. Teaching work. Contrarregulatórios paths.

\section{A avaliação em larga escala como protagonista nos processos educativos: para onde está nos levando?}

As grandes mudanças operadas na economia mundial nas últimas décadas produziram uma verdadeira onda de reestruturações de estados e mercados. Estes processos de reestruturação do mundo produtivo acabaram por reposicionar novas necessidades no campo social, econômico, cultural, ambiental, ético e, obviamente, educacional. As reformas educacionais empreendidas a partir da década de 1990 e extensivas à atualidade fazem-nos refletir sobre suas concepções, suas funções, seus limites, seus interesses. Estas ideias reformadoras seguem os ditames de políticas maiores que envolvem os processos de globalização e de reestruturação do mundo produtivo. Hypolito (2011) considera que o gerencialismo é uma das características que fazem parte dessas reformas e que orienta a organização da gestão pública para uma orientação gerencial, focalizada em eficiência dos serviços e na introdução de mecanismos de mercado na administração pública. Aponta que todo este processo leva a 
educação a assumir papel primordial na perspectiva da constituição de uma hegemonia ideológica conservadora, bem como na perspectiva de instigar movimentos contrahegemônicos. Esta lógica neoliberal e gerencialista interpela os sujeitos, as escolas, os professores e as professoras, no sentido de uma subjetivação que conduz a comportamentos de aceitação e que são muito produtivos para um desempenho das políticas educativas, no sentido de atender ao modelo mercadológico e gerencial das políticas, tanto nos aspectos da gestão, do currículo e das práticas escolares.

É importante considerar que nas arenas de luta por hegemonia a trajetória não é linear. Ela se configura num movimento contraditório caracterizado por discursos diversos e díspares acerca das questões econômicas, culturais, sociais e políticas. Há, portanto, uma coexistência entre os discursos hegemônicos e os contra-hegemônicos, tornando-se difícil definir suas fronteiras, por serem incertas e imprecisas.

No contexto brasileiro, articuladas às definições internacionais, as políticas de avaliação em larga escala, ou também chamadas de avaliações externas ${ }^{2}$, assumem centralidade como direcionadoras das políticas dos processos educacionais, das estratégias voltadas para a ampliação do controle, de consecução de metas quantitativas no cenário nacional/internacional e de regulação do sistema educacional, bem como do controle do trabalho de gestores escolares e docentes. Neste quadro, já é possível identificar possíveis impactos, significados e efeitos que estas avaliações vêm produzindo no sistema educacional brasileiro e, de forma mais específica, no trabalho docente.

O protagonismo assumido pela avaliação em larga escala, nas últimas décadas, cada vez mais, define políticas públicas educacionais, interfere no cotidiano escolar e afeta diretamente o trabalho docente, dotando-lhe de novas feições. Como constituintes das políticas reformadoras maiores da educação, as políticas de avaliação têm sido encorpadas, fortalecidas, consolidadas e parecem não apresentar sinais de declínio. De acordo com Afonso (2010), o foco dado às avaliações sistêmicas, em diversos contextos nacionais/internacionais, indica caminhos de expansão para domínios diversos e para além do campo da educação.

A avaliação assumida como processo de controle transforma-se em instrumental de grande relevância da gestão pública, dotando-a de novas roupagens: administração

\footnotetext{
${ }^{2}$ Consubstanciam-se em aplicação de testes padronizados que são elaborados fora do ambiente da escola, normalmente, por técnicos e empresas contratadas para realizar todo o processo. As escolas, assim, não colaboram em nada para os testes.
} 
gerencial, controle, regulação, eficiência, eficácia, excelência, competitividade e responsabilização, principalmente, dos profissionais docentes. Diversos países, pressionados a estabelecerem metas para o alcance da qualidade da educação, têm atribuído às avaliações padronizadas, ora nomeadas de exames nacionais, a responsabilidade de produzir informações confiáveis sobre o desempenho dos alunos e, consequentemente, a responsabilidade de "contribuir para melhorar a qualidade do ensino e das escolas." (FERNANDES, 2009).

Contraditoriamente, críticas substantivas têm sido produzidas a vários países que consideram esta centralidade da avaliação como forma de monitorar o desempenho discente e dos sistemas. De acordo com Fernandes (2009), países como Inglaterra, Estados Unidos, Holanda, França e Austrália, mesmo com muitos anos de existência dos exames nacionais, têm apresentado resultados bastante modestos em relação aos avanços na educação. As críticas recaem, substancialmente, sobre os processos de empobrecimento do currículo, tendo em vista que os conhecimentos desenvolvidos no espaço da escola reduzem-se "ao que cai no exame". Para Freitas (2012) além do estreitamento curricular, outras críticas se evidenciam: incremento da competitividade entre docentes e escolas; pressão sobre o desempenho dos alunos e preparação para os testes; estratégias fraudulentas para alcançar maiores índices; aumento da segregação socioeconômica em diversas esferas; precarização da formação docente; destruição moral do professor; destruição do sistema público de ensino e, por fim, ameaça à própria noção liberal de democracia.

Assim, as políticas de avaliação têm provocado, também, debates diversos sobre suas implicações, seus impactos nas redes e no trabalho dos professores, seus limites e suas potencialidades. Diversos estudos e pesquisas mais recentes já apontam alguns aspectos que envolvem as implicações que a cultura dos exames tem produzido no interior das redes e das escolas (SOUSA, OLIVEIRA, 2010; ESQUISSANI, 2010; WERLE, 2011; SHIROMA, SCHNEIDER, 2011).

As práticas avaliativas são muito antigas e, em seu cerne, já guiavam processos de seleção, classificação, hierarquização e regulação. Porém, é na modernidade, com o surgimento da indústria, que elas assumem relevância crucial com o propósito de verificar os resultados das ações de formação ou capacitação com o objetivo de selecionar e classificar os trabalhadores e de produzir informação útil à racionalização da gestão (DIAS SOBRINHO, 2003). No campo educacional, a avaliação assume "lugar privilegiado, não só como prática política e pedagógica, produzindo efeitos 
dentro e fora do âmbito propriamente educacional, mas também como importante campo de estudo." (Ibid., 2003, p. 15).

A avaliação de programas e de sistemas educacionais, entretanto, "remonta, pelo menos, ao início do século 19, desenvolvendo-se a partir de pesquisas empíricas de cunho quantitativo." (BAUER, p. 317, 2010). Para Madaus, Scriven e Stufflebeam (1983 apud BAUER, ibid., 2010, p. 318), os exames escritos, mais do que indicar a ideia de justiça nos julgamentos, servia também para obter provas (informações) para comparar diferentes desempenhos entre escolas. Nos últimos anos do século XIX e nos primeiros 30 anos do século $\mathrm{XX}$ é que a utilização de testes para mensurar conhecimentos ganha centralidade e força.

No século XXI, a avaliação segue consolidando-se como "coluna vertebral", utilizando-se de exames/testes aplicados nacionalmente, enfocando o desempenho cognitivo dos alunos e, consequentemente, com objetivo de avaliar o trabalho docente e as escolas. Esta centralidade na avaliação visa à ampliação do controle sobre as redes, sobre as escolas, sobre o trabalho docente e, em última instância, sobre os alunos para ajustá-los aos princípios reestruturadores de mercado. Neste contexto, para Afonso (2000), a regulação aparece como eixo demarcador da organização dos sistemas educacionais, tendo em vista que a avaliação, com o foco em testes padronizados e resultados, assume funções várias traduzidas em formas e modalidades diversas. Considera que o uso de testes objetivos representa um retorno de alguns pressupostos tayloristas (neo-taylorismo) em que tais testes são dispositivos centrais para mensurar conhecimentos e compor uma maquinaria da avaliação. Freitas (2012) denomina este processo como um movimento neotecnicista. O autor considera que este é um dos efeitos mais fortes percebidos no interior das escolas como parte da política de avaliação em larga escala em que princípios como responsabilização, privatização e meritocracia são eixos estruturadores da reforma empresarial da educação e imprimem uma racionalização nas práticas escolares que materializam-se no controle dos processos, configurados em padrões medidos por testes para garantirem resultados atrelados às concepções de eficácia e eficiência determinadas pelo mercado.

Os resultados da Prova Brasil ${ }^{3}$, desde 2005, e do IDEB (Índice de Desenvolvimento da Educação Básica), a partir de 2007, apontam para a produção de

${ }^{3}$ A Portaria Ministerial no 931 de 21 de março de 2005 modifica o Sistema de Avaliação da Educação Básica SAEB, redefinindo sua composição. A partir da portaria, o SAEB passar a ser composto por dois processos de avaliação: a Avaliação Nacional da Educação Básica - ANEB e a Avaliação Nacional do Rendimento Escolar ANRESC (Prova Brasil). A ANEB mantém os mesmos objetivos, características e procedimentos até então utilizados 
uma multiplicidade de efeitos nas redes de ensino e nas escolas. A divulgação pública dos resultados das escolas configura uma exposição pública que interfere diretamente na sua autoimagem, que resulta, de forma perversa, em premiação ou punição. Os problemas que envolvem a recepção, a apropriação e a interpretação dos resultados promovem sentidos diferenciados e interferem diretamente na vida de alunos, professores e gestores. Para Fernandes (2009, p. 121), verifica-se que a lógica dos exames, implementados nos diversos países apresentam modalidades diversas, com "funções, formatos, propósitos e forma de controle, de acordo com as políticas educacionais dos diferentes países e das prioridades ou objetivos que definem." Além disso, o autor aponta que os efeitos desta lógica são amplamente documentados e conhecidos: efeitos na vida social, pessoal e acadêmica dos estudantes; na organização da escola e do trabalho docente no processo de desenvolvimento do currículo; no que e como se ensina; no que e no como se avalia e, por fim, na credibilidade social dos sistemas educativos.

Ao lado destes efeitos, outros parecem se concretizar no cotidiano escolar. Garcia (2008) faz uma análise crítica da avaliação centralizada no processo de supervisão e controle, indicando sua preocupação com a cultura da medida como modo de avaliar as aprendizagens e a escola. Para a autora, o sistema de avaliação imposto no Brasil, dos anos iniciais do ensino fundamental até a pós-graduação, desconsidera uma cultura pedagógica constituída historicamente pelo coletivo de educadores e enfatiza aspectos técnicos, estatísticos e de medidas para atender a padrões internacionais da educação. A cultura da testagem produz um reducionismo dos processos educativos e pedagógicos. Dessa forma,

[...] o prazer de aprender desaparece quando a aprendizagem é reduzida a provas e notas; os alunos passam a estudar 'para se dar bem na prova' e para isso têm de memorizar as respostas consideradas certas pelo professor ou professora. Desaparecem o debate, a polêmica, as diferentes leituras do mesmo texto, o exercício da dúvida e do pensamento divergente, a pluralidade. A sala de aula torna um pobre espaço de repetição, sem possibilidade de criação e circulação de novas ideias. (GARCIA, 2008, p. 35)

pelo SAEB (Caráter amostral). A ANRESC, popularmente conhecida como Prova Brasil, foi realizada pela primeira vez em 2005 com o objetivo de avaliar a qualidade do ensino ministrado em cada unidade escolar. Trata-se de um exame com abrangência de todo o sistema nacional de educação, é aplicado a cada 2 anos, avaliando habilidades de leitura e de resolução de problemas. É aplicado aos alunos de $4^{\mathrm{a}}$. série (ou $5^{\circ}$. ano) e $8^{\mathrm{a}}$. séries (ou $9^{\circ}$. ano) do Ensino Fundamental de escolas públicas. As portarias n ${ }^{\circ} 69$ de 04 de maio de 2005 e a nº 89 de 25 de maio de 2005 detalham as finalidades e procedimentos da ANRESC e da ANEB. 
Os testes estandardizados, tomados como parte do arsenal da avaliação, assumem claramente função reguladora. Seu caráter psicométrico aponta para uma intenção de garantir a padronização dos procedimentos avaliatórios e a homogeneização das condições de respostas aos testes, o que significa homogeneizar o currículo. As proposições de avaliação, nestas condições, negam a possibilidade das diferenças entre sujeitos, estados, regiões, localidades, etc. Estabelece, portanto, padrões de comportamento e conhecimentos uniformes em todo o território nacional. Esteban (2012) considera que os processos avaliativos, nestes termos, pautam uma norma que funciona como força impositiva em que são reconhecidos aqueles que se encontram dentro do padrão definido. Aqueles que se afastam são desqualificados e excluídos.

Neste cenário, consideramos de capital importância identificar e compreender que efeitos as avaliações em larga escala têm promovido no trabalho docente. Para tanto, é relevante que a investigação não se situe apenas nos momentos de realização da Prova Brasil, mas nos processos que a antecedem e que a sucedem. Assim, questões instigantes têm nos orientado em nossas pesquisas: As escolas consideradas "de qualidade" são aquelas que se destacam pelo melhor IDEB? As escolas "sem qualidade" são escolas que não obtém alto IDEB? O que define, efetivamente, uma escola "de qualidade" ou "sem qualidade"? Em relação a que elas apresentam ou não "qualidade" ?

É importante salientar que o IDEB é um indicador calculado a partir dos resultados da Prova Brasil (média dos exames em Língua Portuguesa e Matemática) e do fluxo escolar (taxas de aprovação, reprovação e evasão). Logo, o que define a qualidade da escola, conforme o IDEB, é a correlação entre desempenho nos componentes avaliados e o fluxo escolar, o que consideramos uma redução para definir a qualidade ou não de uma instituição complexa como a escola.

Discutir as implicações que as avaliações provocam no trabalho docente é o objetivo deste artigo ${ }^{4}$. Desenvolvemos a pesquisa em escolas de duas redes municipais localizadas na Baixada Fluminense, região metropolitana e periférica do Rio de Janeiro e procurou investigar os sentidos e os efeitos que os resultados das avaliações externas, na educação básica, têm provocado no desenvolvimento do trabalho docente, focalizando na perspectiva de gestores escolares e professores. A questão disparadora de nossa investigação girou em torno deste objetivo: como os resultados dos testes

\footnotetext{
${ }^{4}$ Apresenta a discussão de dados obtidos em observações e entrevistas semiestruturadas (2 Diretoras e 7 professoras) realizadas em duas escolas públicas da região metropolitana do Rio de Janeiro, como parte da Pesquisa "Observatório das Periferias Urbanas" (Observatório da Educação - INEP/CAPES).
} 
estandardizados e do IDEB (Índice de Desenvolvimento da Educação Básica) ${ }^{5}$ têm interferido no trabalho docente desenvolvido em suas salas de aula?

A partir desta questão, outras se colocaram para orientar nossos olhares: de que forma os testes estandardizados e o foco em resultado tem afetado o trabalho docente no cotidiano escolar? Que mudanças os testes aplicados para aferir o nível de desempenho dos alunos têm provocado na organização do trabalho pedagógico e na regulação e controle do trabalho docente? Que dimensões contrarregulatórias podem ser potencializadas para construir uma proposta alternativa de avaliação voltada para a qualidade socialmente referenciada da educação que tome desenvolvimento da escola, dos professores e dos alunos como eixo central?

Vislumbrar as tecnologias políticas implementadas por meio das políticas de avaliação é necessário para perceber referências relativas aos conceitos de regulação, performatividade e responsabilização como tecnologias políticas a serviço dos ideais dos reformadores empresariais. Alguns achados permitem indagar que conformações assumem o trabalho do professor diante da interferência dos testes em seu cotidiano. Problematizaremos os efeitos regulatórios que estes exames produzem no trabalho pedagógico, bem como evidenciamos os aspectos que emergem da realidade como indícios de controle, performatividade, intensificação do trabalho docente e cenários de responsabilização unilateral.

A partir de uma posição propositiva, procura-se discutir, a partir de movimentos contrarregulatórios, os desafios que se colocam para construir uma educação de qualidade socialmente referenciada para todos. Trata-se, portanto, de pensar em "outras formulações mais consequentes" (FREITAS \& SORDI, 2013, p. 88), em que as avaliações estejam a serviço do desenvolvimento da escola, do professor e do aluno. Procura-se, assim, indicar potencialidades de se constituir experiências de avaliação formativa (AFONSO, 2000, 2010).

\section{A cultura dos exames como indutora do controle do trabalho docente: regulação, performances e responsabilização}

A ampla disseminação de exames/testes como sinônimos de avaliação, no Brasil, é notória ${ }^{6}$. Nos sistemas estaduais e municipais, sob um efeito replicante, há uma

${ }^{5}$ Criado em 2007 para aferir a qualidade da educação brasileira focalizando duas variáveis: fluxo escolar e notas de desempenho dos alunos em Língua Portuguesa e Matemática, aferidas em teste nacional denominado "Prova Brasil", aplicado bianualmente aos alunos de $5^{\circ}$ e $9^{\circ}$. ano do ensino fundamental. 
verdadeira disseminação do modelo central de avaliação que indica características regulatórias e de maior controle com intenções explícitas de transformar a educação num grande mercado (AFONSO, 2000, 2010; FERNANDES, 2009; BALL, 2005; DÍAZ BARRÍGA, 2009; DIAS SOBRINHO, 2003).

Sob o discurso retórico da qualidade da educação, a palavra avaliação ganhou proporções gigantescas para resolver as mazelas e problemas da educação brasileira. Afonso (2007) define que este agigantamento configura um largo movimento de “obsessão avaliativa". O autor informa que alguns modos de imputar responsabilidades à escola e a seus docentes, por meio de avaliações sistêmicas e estandardizadas, transformaram-se numa panaceia ou mesmo num fetiche, "pelo facto de a avaliação, a prestação de contas e a responsabilização serem, supostamente, capazes de, por si sós, satisfazer as expectativas de grupos e setores sociais aparentemente desejosos de resolver os défices e problemas de qualidade da educação pública" (AFONSO, 2012, p. 472).

Em sua revisão do conceito de regulação, Barroso (2005) focaliza a polissemia do termo, estabelecendo significados muito próximos ao de controle, de normatizações, de ajustes, de adequações aos padrões definidos centralmente. Em seu estudo, considera que, diante da multiplicidade de concepções, seria mais prudente falar em "multiregulação", tendo em vista a diversidade de fontes e formas de regulação. Nessa perspectiva, a regulação compreende processos múltiplos, contraditórios. Em linhas gerais, o autor considera que a regulação é um dispositivo que funciona, não só como normatizador (regras, regulamentos, injunções, etc.) dos sistemas educativos, mas, também, que procura (re)ajustar as ações diversas dos sujeitos em função dessas mesmas normas.

O discurso oficial, sustentado na retórica do direito à aprendizagem e da qualidade da educação, aponta para a implementação de uma política de avaliação sistêmica assentada, essencialmente, nas funções da regulação da gestão e do trabalho docente e da mensuração de desempenhos. Assim, confere-se aos exames confiabilidade, legitimidade e fidedignidade técnica para definir as performances da escola e do docente. No quadro das reformas, há um conjunto de mudanças que atingem as estruturas do Estado dotando-o de novas funções e responsabilidades coadunadas com os processos reestruturadores do mundo capitalista.

${ }^{6}$ Prova Brasil ${ }^{6}$, ENEM (Exame Nacional do Ensino Médio), Provinha Brasil ${ }^{6}$, ANA (Avaliação Nacional da Alfabetização), ENCCEJA (Exame Nacional de Certificação de Competências de Jovens e Adultos). 
Conforme Ball (2004, p. 1106), estas configurações surgem "de mudanças nos papeis do Estado, do capital, das instituições do setor público e dos cidadãos e nas suas relações entre si [...]”. As mudanças se dão, inicialmente, no movimento de passagem “do Estado como provedor para o Estado como regulador, estabelecendo as condições sob as quais vários mercados internos são autorizados a operar.” (BALL, 2004). A partir daí, um conjunto de ações desencadeia-se no sentido de tornar o Estado eficiente, eficaz e ágil: avaliação de desempenho de alunos, responsabilização de escolas e professores, implantação de políticas de bonificação/premiação docente, redefinição das funções de gestores, etc.

Segundo Afonso (2000), desde a década de 1980, o foco dado à avaliação, principalmente, por parte de governos neoconservadores e neoliberais foi a conformação de um "Estado avaliador" em que a adoção de princípios competitivos, da lógica de mercado e por meio da inserção de modelos da gestão privada no espaço público, enfatizando o alcance de metas e resultados, tornaram-se essenciais para o fortalecimento do discurso da eficiência sob a ótica empresarial.

Assim, a inserção de uma cultura gerencialista empresarial no setor público promoveu uma verdadeira invasão de instrumentos de regulação, performances e responsabilização. A avaliação em larga escala, pautada no estabelecimento de indicadores para medir desempenhos dos alunos, performances das escolas e de seus professores, torna-se mecanismo essencial para legitimar o controle do trabalho docente em resultados aferidos nos testes padronizados. Este movimento reformador atual baseado na lógica de responsabilização, de meritocracia e gerencialismo se sustenta numa lógica racionalista de constituição de standards, que medem e estabelecem metas para serem aferidas em testes padronizados, "com ênfase nos processos de gerenciamento da força de trabalho da escola (controle pelo processo, bônus, punições), ancorada nas mesmas concepções oriundas da psicologia behaviorista, fortalecida pela econometria, ciências da informação e de sistemas, elevado à condição de pilares da educação contemporânea." (FREITAS, 2012, p. 383).

Este processo de reestruturação do Estado impõe redefinições nas funções de diversos sujeitos. Os professores e gestores passam a constituir-se como corpo central para a implementação do projeto neotecnicista (FREITAS, 1992, 1995; AFONSO, 2000). Meritocracia, responsabilização, privatização, qualidade, eficácia, eficiência, performance, competência e testes compõem o amplo espectro lexical da 
competitividade e da lógica empresarial na educação (AFONSO, 2010; FREITAS, 2012; PACHECO, PESTANA, 2014).

A eficácia e eficiência exigidas das escolas e dos docentes evidenciam as novas funções a serem assumidas e impõem uma autoimagem que desvaloriza as subjetividades envolvidas no processo educacional. Uma das diretoras aponta estes sentimentos. Para ela,

Os professores têm se esforçado muito para melhorar os resultados. Mas, quando os resultados são divulgados, há um cenário desolador. A frustração é clara no rosto de todas aqui da escola. (Diretora, Escola B).

Duas professoras entrevistadas também mostram sua preocupação com as exigências que os resultados que os alunos alcançam nos testes também são extensivos ao seu trabalho:

Há uma grande pressão para melhorar o Ideb. A Secretaria cobra da diretora e ela acaba exigindo de nós que os alunos se saiam bem na Prova Brasil. Quando fica mais próximo, mais nós somos pressionadas a melhorar os resultados. Parece que nosso trabalho é só treinar para que os alunos tirem notas altas no teste. (Professora 1, Escola B).

Eu fico muito preocupada com todas estas avaliações. Não sei até que ponto elas expressam o que nossos alunos sabem e, o pior, tenho certeza de que elas não avaliam nosso trabalho. Parece que, a todo momento, tenho que ser "exemplar", uma professora impecável. Mas, como? Há uma série de problemas familiares, sociais e econômicos que interferem nas aprendizagens dos alunos (Professora 2, Escola $B)$.

Se instala, assim, uma "cultura da performatividade", na qual o professor é o protagonista e é convocado a apresentar desempenhos cada vez mais eficazes e eficientes (BALL, 2004, 2005, 2011). Considera que as performances dos indivíduos ou de organizações atuam como parâmetros de produtividade ou de resultado, ou atuam como indicativos de 'qualidade' ou 'momentos' de promoção ou inspeção. Além disso, "significam, englobam e representam a qualidade, a validade e ou valor de um indivíduo ou organização dentro de um determinado âmbito de julgamento/avaliação" (BALL, 2005, p. 543). Seguindo a lógica do desempenho e do alcance de resultados, a necessidade de reestruturação produtiva e das funções do Estado regulador provocaram o surgimento de novas tecnologias de controle. Neste contexto, a avaliação ganha destaque considerável por ser um mecanismo que objetiva o controle para atingir metas definidas pelo poder central, a efetividade e a qualidade, criando uma lógica performativa do trabalho docente. A intensificação do trabalho, em busca de melhores 
resultados é a materialização dessa "corrida performativa". Exemplos dessa intensificação mostram-se nestes relatos:

Virou uma loucura o nosso trabalho! Não faço mais nada além de preparar para a Prova Brasil. Na escola, fazemos simulados todo mês. Tem sido muito estafante porque a gente tem que elaborar os simulados, corrigir, preencher fichas. (Professora 1, Escola A).

Me sinto muito cobrada e pressionada para melhorar a nota na Prova Brasil. Estou trabalhando muito, pois muitos alunos têm grandes dificuldades em leitura e interpretação. Este ano, como vai ter Prova Brasil, tudo tem que estar voltado pra ela, principalmente, porque nossa escola não vai bem no Ideb. (Professora 3, Escola B).

A performatividade, como uma tecnologia política, envolve caráter de racionalização técnica e instrumentalização dos processos, além de expor o conhecimento e sua condição de mercadoria no quase-mercado (BALL, 2005). A performatividade é alcançada quando são construídos e disseminados indicadores e informações que permitam a publicidade de escolas, como instrumentos de estímulo, julgamento, premiação, punição e comparação entre profissionais e instituições. Isto se dá na ampla divulgação de resultados nas avaliações em larga escala, o que produz a elaboração de rankings, exaltando as primeiras colocadas, consideradas escolas melhores e de qualidade; e as demais como incompetentes, ineficientes e sem qualidade.

As tecnologias políticas não são apenas instrumentos para promover mudanças técnicas e estrutural das escolas. Elas objetivam, também, "reformar" os docentes e, assim, alterar o sentido do que é ser professor, ajustando-os aos ditames gerencialistas para melhorarem as performances (altos desempenhos) em busca de resultados. Para Afonso (2000, p. 40), a política de avaliação pautada em alcance de metas e de resultados interfere e condiciona diretamente as práticas pedagógicas dos profissionais, gerando efeitos de considerável pressão sobre o trabalho docente, o que o torna um "treinador para os testes". Dessa forma, tais tecnologias acabam por contribuir, incisivamente, na desprofissionalização docente.

Estudos e pesquisas recentes (AUTOR/a, 2013a, 2013b; ASSUMPÇÃO, 2013; MOTA, 2013; LINO, 2014; MELO, 2014), que tomam as escolas de periferia como campo, indicam que a cultura do exame vem repercutindo de forma contumaz e insistente no cotidiano da escola, alterando práticas, fazeres e saberes. Este quadro implica na redução das funções docentes à mera execução de decisões centrais. Tornase, assim, um mero "aplicador" de testes, desprofissionalizando-se, reificando-se. Os 
achados têm indicado que há um cenário bastante preocupante associado aos aspectos apresentados por Freitas (2012): estreitamento curricular, competitividade entre docentes e escolas, preparação e treinamento para os testes, cobranças pelo alcance de metas e desempenhos, precarização do trabalho docente, dentre outros.

A eficácia e eficiência exigidas do gestor e do professor no trabalho pedagógico da escola se evidenciam nestes depoimentos:

Os professores têm se esforçado muito para melhorar os resultados. Mas, vejo que o trabalho deles tem se restringido à execução do que é passado pela Secretaria. Há um excesso de questões objetivas nas avaliações feitas pelo professor, seguindo o mesmo modelo da Prova Brasil. (Diretora, Escola A).

Eu não faço mais nada além de preparar para a Prova Brasil. Na escola, fazemos simulados todo mês. Nosso trabalho está centrado nesta prova. Nosso trabalho se limita às disciplinas de Português e Matemática. (Professora 2, Escola A).

Eu me sinto cobrada e pressionada para melhorar a nota na Prova Brasil. Não tenho autonomia para avaliar nossos alunos dentro de uma visão formativa, mais global. (Professora 3, Escola A).

Não sei mais o que fazer. Nós temos um dos menores ideb do município. Somos muito mal vistos na Secretaria e pelas outras escolas. Parece que não trabalhamos aqui. Não acho que a qualidade só é uma medida que se tira nas notas dos testes. (Professora 4, Escola B).

Esta dinâmica cria, cada vez mais, um processo de responsabilização dos docentes, pais, alunos e da escola pelos resultados, retirando todo e qualquer compromisso do Estado com a qualidade da escola pública. O foco na responsabilização de escolas e seus docentes no sucesso ou fracasso dos alunos nos testes estabelece um cenário de "falsa descentralização", pois o Estado exime-se de qualquer responsabilidade sobre a infraestrutura das unidades escolares e transfere para os sujeitos da ponta toda a carga de compromisso pela "aprendizagem" ou "não aprendizagem" dos alunos, independentemente dos contextos, das diferenças e situações vivenciadas no cotidiano.

Na tentativa de vislumbrar compromissos assumidos coletiva e horizontalmente, sem isentar o Estado da sua reponsabilidade de prover os sistemas para que se construa uma qualidade social da educação, discuto, a título de conclusão, algumas potencialidades de práticas avaliativas articuladas à necessidade de uma "accountability 
alternativa" (AFONSO, 2012) que esteja voltada para o desenvolvimento da escola, de seus docentes e de seus alunos em amplos processos de negociação coletiva.

\section{Considerações finais: buscando caminhos da contrarregulação}

Persistem, ainda, graves problemas de fluxo, de evasão, de estrutura das escolas, de carência material, de gestões atreladas a poderes políticos locais, de projetos e programas desarticulados e sobrepostos, de formação insuficiente dos professores, de condições adversas, de baixa remuneração dos profissionais da educação, de desvalorização e precarização do trabalho pedagógico. Estes problemas afetam diretamente a qualidade e não podem ser enfrentados apenas com ampla disseminação de testes para aferir desempenhos, divulgação de resultados, responsabilização de escolas, professores/as e gestores/as.

Os discursos eficientistas das avaliações e da defesa da qualidade da educação pública desconsideram os movimentos dinâmicos que ocorrem cotidianamente na escola. As implicações decorrentes destes discursos no espaçotempo escolar permitem perceber um quadro de grande complexidade que não representa apenas a incorporação acrítica destes discursos, mas também resistências, movimentos, dinâmicas que correm em direção contrária aos ditames mercadológicos. No interior das escolas, professores e professoras, diretores e diretoras, orientadores e orientadoras lidam diariamente com possibilidades outras de construir uma escola de qualidade. "Não perder um aluno para o tráfico", como vimos na narração inicial deste artigo, é um dos inúmeros indicadores que podem potencializar a concepção de qualidade socialmente referenciada. É neste cenário que nos questionamos: diante do quadro de pretenso consenso em relação à cultura do exame, às lógicas eficientistas e empresariais, não é possível vislumbrar espaços de negociação e de construção de outros modelos?

Os sujeitos que se encontram no espaço da escola não apenas assumem as regras de forma verticalizada e hierárquica. Para Werle, Scheffer e Moreira (2012), estes sujeitos podem ignorar ou redefinir normas individual ou coletivamente, explícita ou subliminarmente.

A escola, como um espaço de prática, pode ser um locus de resistência à reprodução normativa, o que decorre do importante papel dos atores, suas negociações e insurgências, uma vez que a ação organizacional não ocorre por referência direta a regras formais, legais, produzidas de forma supraorganizacional. (WERLE, SCHEFFER \& MOREIRA, 2012, p. 21) 
Isso implica em pensar a escola, como espaço de contradições, não é apenas um instrumento reprodutor/realizador das políticas definidas centralmente. Neste sentido, há espaços de contrarregulação que se configuram de formas múltiplas no cotidiano escolar. Freitas e Sordi (2013) apontam que, num caminho oposto à lógica do controle da escola e do trabalho docente por meio de índices e testes há possibilidades de se construir alternativas que apontem para uma responsabilização alternativa (AFONSO, 2010, 2012).

Menos notadas que os atalhos milagrosos, é possível, no entanto, encontrar no cenário nacional e internacional outras formulações mais consequentes para alavancar as reformas educacionais necessárias e que têm demonstrado serem mais eficazes para melhorar a qualidade da educação. (FREITAS e SORDI,2013, p.88)

Se os profissionais docentes não se reconhecem como pensadores e participantes das decisões relativas à organização escolar, ao currículo, às práticas pedagógicas e, naturalmente, à avaliação, obstáculos podem surgir para o alcance dos objetivos e funções educativas. Toda e qualquer ação e/ou política tem maior potencialidade se integrada à instituição, de forma coparticipativa, corresponsável, coletiva e num clima de confiança e pertencimento. Para os autores, caminhar numa direção contrarregulatória envolve a combinação de quatro elementos: respeito, competência, consideração para com os outros e integridade.

Isso implica pensar que a qualidade envolve a valorização das relações entre as pessoas, ou seja, os resultados quantitativos são consequência das relações e não o inverso. Para tanto, a responsabilidade pela qualidade articula a participação do Estado com ator fundamental de um dos polos da negociação. A escola e a comunidade formam o outro polo deste processo. Com o desafio de distinguir o que dos resultados das avaliações externas é indicador de qualidade da educação do que é parte do discurso da excelência ${ }^{7}$, voltamo-nos para o esclarecimento de Silva (2009, p. 223), "a qualidade social na educação não se restringe a fórmulas matemáticas, tampouco a resultados estabelecidos a priori e a medidas lineares descontextualizadas".

Considerar os movimentos reais que acontecem na escola e que as informações produzidas pelas avaliações externas possam ser tomadas como indicadoras para a apropriação de seus problemas, a partir do diálogo constante com práticas cotidianas da avaliação interna, é salutar. Esta relação deve propiciar um ambiente reflexivo da

${ }^{7} \mathrm{O}$ discurso da excelência é também um discurso moral que culpabiliza os indivíduos pela crise e pelo fracasso das instituições, ao mesmo tempo em que apela a que esses mesmos indivíduos sejam mais produtivos e mais responsáveis. 
instituição escolar, levantando e definindo outros indicadores que não se restrinjam ao desempenho dos alunos e ao fluxo escolar, apenas (SORDI, 2012, p. 487). Para a autora, não se trata de desconsiderar a necessidade do uso de informações de medida como elementos da avaliação, mas trata-se de compreendê-las como insuficientes e destinadas a outras finalidades, acionando uma complexa rede interpretativa e problematizadora.

É necessário que os movimentos reais que acontecem na escola e que as informações produzidas pelas avaliações externas possam ser tomadas como indicadoras para a apropriação de seus problemas, a partir do diálogo constante com práticas cotidianas da avaliação interna.

É preciso apontar caminhos alternativos de responsabilização e de regulação da qualidade da escola pública que se constituam como reação aos modelos de avaliação centrados em resultados dos estudantes em testes padronizados. Para Afonso (2010), é necessário pensar em alternativas de accountability como possibilidade de uma concepção mais ampliada, democrática, que inclui a avaliação, a prestação de contas e a responsabilização como elementos abertos, problematizáveis e disponíveis para se aperfeiçoarem, sustentados em aspectos ético, cidadãos, participativos, coletivos, focalizados no direito à informação, à transparência e à justiça. Ela deve assumir potencialidades alternativas que envolvam uma "accountability" inteligente, alternativa e negociada. (AFONSO, 2012; SORDI, 2012; BONDIOLLI, 2004)

Por fim, os projetos de avaliação alternativos que tomem a escola e seus docentes, bem como os demais sujeitos, como centros de referência para discutir, problematizar e pronunciar-se sobre o tipo de qualidade que almejam tornam-se instrumentos de contrarregulação (FREITAS, 2007). A avaliação, seja ela externa, interna ou da aprendizagem, deve fazer parte do processo pedagógico articulando objetivos e finalidades da educação, com os pressupostos da avaliação formativa que superem o paradigma da competitividade que invisibiliza algumas escolas e visibiliza outras (AMARO, 2011, 2013a, 2013b). Assim, a lógica dos exames não contribui para o desenvolvimento e avanço da qualidade das escolas, das aprendizagens e do trabalho docente. Somente fundados na perspectiva de avaliar formativamente e baseados nos princípios da qualidade negociada - democracia, participação, é que se pode pensar em processos compartilhados, corresponsáveis e participativos de melhoria da qualidade da educação. 


\section{REFERÊNCIAS}

AFONSO, A. J. Política educativas e auto-avaliação da escola pública portuguesa: apontamentos de uma experiência. Est. Aval. Educ., São Paulo, v. 21. N. 46, p. $343-$ 362, maio/ago, 2010.

AFONSO, A. J. Avaliar a escola e a gestão escolar: elementos para uma reflexão crítica.In: ESTEBAN, M. T. (org.). Escola, currículo e avaliação. 3. Ed., São Paulo: Cortez, 2007.

AFONSO, A. J. Avaliação educacional: regulação e emancipação. São Paulo: Cortez, 2000.

ASSUMPÇÃO, E. de A. C. A correlação das práticas avaliativas no interior da escola com a política de controle público por meio da avaliação: um estudo em Duque de Caxias/RJ. 2013. 108 f. Dissertação (Mestrado em Educação). Faculdade de Educação. Universidade Federal do Estado do Rio de Janeiro (UNIRIO), Rio de Janeiro.

BALL, S. J. Sociologia das políticas educacionais e pesquisa crítico-social: uma revisão pessoal das políticas educacionais e da pesquisa em política educacional. In: BALL, S. J. MAINARDES, J. (Orgs.) Políticas educacionais: questões e dilemas. São Paulo: Cortez Editora, 2011.

BALL, S. J. Profissionalismo, gerencialismo e performatividade. Cadernos de Pesquisa, São Paulo-SP, n. 126, p. 539-564, set./dez, 2005.

BALL, S. J. Reformar escolas/reformar professores e os terrores da performatividade. Revista Portuguesa de Educação, año/vol. 15, número 002, Universidade do Minho, Braga, Portugal, pp. 3-23,2004.

BARROSO, J. O Estado, a educação e a regulação das políticas públicas. Educ. Soc., Campinas, vol. 26, n. 92, p. 725-751, Especial - Out. 2005. Disponível em:

<http://www.cedes.unicamp.br >. Acesso em: 20 out. 2010.

BAUER, A. Usos dos resultados das avaliações dos sistemas educacionais: iniciativas em curso em alguns países da América Latina. Revista Brasileira de Estudos

Pedagógicos, Brasília, v. 91, n. 228, p. 315-344, maio/ago. 2010.

BONDIOLI, A. (org.). O projeto pedagógico da creche e a sua avaliação: a qualidade negociada. Campinas-SP: Autores Associados, 2004.

DIAS SOBRINHO, J. Avaliação: políticas educacionais e reformas da educação superior. São Paulo: Cortez, 2003.

DÍAZ BARRIGA, A. A avaliação na educação mexicana: excesso de programas e ausência da dimensão pedagógica. Sísifo. Revista de Ciências da Educação, v. 9, pp. 19-30.. Disponível em: 〈http://sisifo.fpce.ul.pt〉. Acesso em 20 mar. 2011

ESTEBAN, M. T. A avaliação no cotidiano escolar. IN: ESTEBAN, M. T. (Org.). Avaliação: uma prática em busca de novos sentidos. 5. Ed., p. 7-24, Petrópolis: DP et Alii, 2008.

ESQUINSANI, R. S. S. Performatividade e educação: a política das avaliações em larga escala e a apropriação da mídia. Práxis Educativa, Ponta Grossa, v.5, n.2, p. 131-137, 
jul.-dez. 2010. Disponível em<http://www.periodicos.uepg.br〉. Acesso em: 06 de set. de 2013

FERNANDES, D. Avaliar para aprender: fundamentos, práticas e políticas. São Paulo: Editora UNESP, 2009.

FREITAS, L. C. de. et.al. Avaliação educacional: caminhando pela contramão. Petrópolis-RJ, Vozes, 2009.

FREITAS, L. C. de. et.al. Ciclos, seriação e avaliação: confronto de lógicas. São Paulo: Moderna, 2003.

FREITAS, L. C. de. et.al. Crítica da organização do trabalho pedagógico e da didática. Campinas: Papirus, 1995.

FREITAS, L. C. de.; SORDI, M. R. L. de. Responsabilização participativa. Revista Retratos da Escola, Brasília, v. 7, n. 12, p. 87-99, jan./jun. 2013.

GARCIA, R. L. A avaliação e suas implicações no fracasso/sucesso. In: ESTEBAN, M. T. (Org.). Avaliação: uma prática em busca de novos sentidos. 5. Ed., Petrópolis: DP et Alii, p. 25-42, 2008.

HYPOLITO, A. Reorganização gerencialista da escola e trabalho docente. Educação: teoria e prática, v. 21, n. 38, Rio Claro, SP, out./dez. 2011. Disponível em: < http://educa.fcc.org.br/pdf/eduteo/v21n38/v21n38a06.pdf > Acesso em 23 abr. 2013.

LINO, C. de S. Qualidade na escola e qualidade da escola: as repercussões da cultura do exame em duas escolas públicas de Duque de Caxias. 2014. $131 \mathrm{f}$. Dissertação (Mestrado em Educação, Cultura e Comunicação em Periferias Urbanas). Faculdade de Educação da Baixada Fluminense. Universidade do Estado do Rio de Janeiro (UERJ). Rio de Janeiro.

MELO, L. P C. de. Movimentos discursivos nas vozes dos sujeitos da Prova Rio. 2014. 148 f. Dissertação (Mestrado em Educação, Cultura e Comunicação em Periferias Urbanas). Faculdade de Educação da Baixada Fluminense. Universidade do Estado do Rio de Janeiro (UERJ). Rio de Janeiro.

MOTA, M. O. Avaliação e cotidiano escolar: usos e desusos da Provinha Brasil na alfabetização. 2013. 174 f. Dissertação (Mestrado em Educação, Cultura e Comunicação em Periferias Urbanas). Faculdade de Educação da Baixada Fluminense. Universidade do Estado do Rio de Janeiro (UERJ). Rio de Janeiro.

PACHECO, J. A.; PESTANA, T. Globalização, aprendizagem e trabalho docente: análise das culturas de performatividade. Educação, Porto Alegre, impresso, v. 37, n. 1, p. 24-32, jan./abr.2014.

SAUL, A. M. Avaliação emancipatória: desafios à teoria e à prática de avaliação e reformulação do currículo. São Paulo: Cortez, 1995.

SHIROMA, E. O. SCHNEIDER, M. C. Professores em exame: reflexões sobre práticas de avaliação docente. Práxis Educativa, Ponta Grossa, v.6, n.1, p. 31-44, jan.-jun. 2011. Disponível em <http://www.periodicos.uepg.br. $>$ Acesso em 06 de set. 2013. 
SILVA, M.A. Qualidade social da educação pública: algumas aproximações. Cad. Cedes, Campinas, v.29, n.78, p. 216-226, maio/ago.2009.

SORDI, M. R. L. De. Implicações ético-epistemológicas da negociação nos processos de avaliação institucional participativa. Educ. Soc., Campinas, v. 33, n. 119, p. 485510, abr.-jun. 2012.

SOUSA, S. Z. de. OLIVEIRA, R. P. de. Sistemas estaduais de avaliação: uso dos resultados, implicações e tendências. Cadernos de Pesquisa, v. 40, n. 141, p. 793-822, set./dez., 2010

WERLE, F. O. C. Políticas de avaliação em larga escala na educação básica: do controle de resultados à intervenção nos processos de operacionalização do ensino. Ensaio: aval. pol. públ. Educ., Rio de Janeiro, v. 19, n. 73, p. 769-792, out./dez. 2011.Disponível em: < http://www.scielo.br/pdf/ensaio/v19n73/03.pdf>. Acesso em: 20 mar. 2013.

WERLE, F. O. C. SCHEFFER, L. S.; MOREIRA, M. de C. Avaliação e qualidade social da educação. ETD - Educ. temat. digit., Campinas, SP, v. 14, n. 2, p. 19-37, jul./dez. 2012.Disponivel em: < http://www.

http://www.fae.unicamp.br/revista/index.php/etd/article/view/3193 >. Acesso em 10 jul 2014.

\section{Como referenciar este artigo}

AMARO, Ivan. As políticas de avaliação em larga escala e trabalho docente: dos discursos eficientistas aos caminhos contrarregulatórios. Revista Ibero-Americana de Estudos em Educação, Araraquara, v. 11, n. 4, p. 1960-1978, 2016. Disponível em: <http://dx.doi.org/10.21723/riaee.v11.n4.7155>. E-ISSN: 1982-5587.

\section{Submetido em: agosto/2014}

Aprovação final em: setembro/2016 